\title{
Improving Voltage Stability of Electrical Power System by Optimal Location of FACTS Devices Using an Evolutionary Method
}

\author{
Soufiane Lemdani ${ }^{*}$, Habib Benbouhenni ${ }^{2}$ \\ ${ }^{1}$ Departement d'Electrotechnique , Université de l'USTO-MB, Oran, Algeria \\ ${ }^{2}$ Departement d'Electrotechnique, ENP-MA, Oran, Algeria
}

Corresponding Author Email: lamdaniso@yahoo.fr

https://doi.org/10.18280/ti-ijes.650116

Received: 26 October 2020

Accepted: 15 December 2020

\section{Keywords:}

FACTS, SVC, TCSC, SSSC, STATCOM,

UPFC, IEEE, GA, STABILITY

\section{INTRODUCTION}

In the present time, while the development is taking place, the demand of electricity in the world is simultaneously increasing. The Operation and the planning of greatinterconnected electrical networks (ENs) are becoming more complex. Hence, in 1988, the launch of new technologies FACTS by electric power research institute offered many advances and the ENs are becoming flexible and controllable.

It is very important to know that the best implementation of the flexible systems (FACTS) devices can contribute to improve voltage deviation in all bases of the EN systems. Moreover, voltage deviation in the ENs plays very important role and is considered one of the most complex subjects in the study and analysis of complex power systems [1].

The problem of voltage stability is mainly caused by stressed loading condition of the system. It is essential to analyze the voltage stability for improving the efficiency of the network $[1,2]$. Other authors have conducted many types of research on analysis of voltage stability. In addition, several methods have been proposed to improve the technical performances of the existing power systems.

Several new techniques, to optimize the FACTS systems and to maintain the voltage stability in the networks, have been suggested. For instance, the (PSO) technique and the AGS algorithm are proposed by Inkollu and Kota [2] to improve voltage stability and deviations. Another method to improve voltage stability in EN system, by optimal location of FACTS, has been published by Naganathan and Ranganathan. In the cited research papers, the use of the PSO algorithm as an optimization technique aims to determine a suitable position of STATCOM and UPFC in order to improve voltage stability in IEEE 118Bus and 75Bus power system [3].

Another method, based on the network reconfiguration technique for improving the voltage deviation of the EN systems, has been suggested by Kabir Chakra Borty \& Bijaya Saha [4]. This technique is applied to the 6-Bus 8-line test system.

In this paper, we will implement one of the heuristic methods based on Genetic Algorithms (GA) to determine optimal placements associated with appropriate parameters of FACTS devices in power systems in order to enhance the voltage stability of the EN systems. In our study, different FACTS devices were used in simulation process, such as SVC, TCSC, SSSC, STATCOM, TCVR, TCPST and UPFC. At the end, the optimized placements have been tested in 30,57 and 118 bus test systems.

\section{DESCRIPTION OF FLEXIBLE AC TRANSMISSION SYSTEMS (FACTS) USED IN THE SIMULATION PROCESS}

The FACTS is a device for improving operation and controlling Electrical Network based on the modification of different parameters of the power transmitted equation including voltage, phase angle, and reactance. This new technology participates in the enhancement of many operations in the EN system such as controlling active and reactive power flow, minimizing active losses in the transmission line and improving technical performance in power system. Indeed, the manner to set up this FACTS device technology with suitable locations and parameters is the actual subject of many research studies; in this context, several research papers have been published and the results have been presented in different international journals $[5,7,16]$.

\subsection{Static VAR compensator (SVC)}

The SVC is a device of the (FACTS) systems family, which 
uses power electronics to control power flow on electrical networks. The SVC could be used to regulate voltage in EN buses with the reactive power injected or absorbed from the network. Many research papers, such as Tran Thi Ngoat, Le Ngoc Giang and other $[8,14,15]$, have been published in the area of FACTS devices incorporation for enhancing the operation of electrical power systems.

\subsection{Thyristor controlled serie compensator (TCSC)}

The use of the TCSC in series with transmission line can increase its capability to carry the active power by modifying artificially its reactance [9].

\subsection{Static synchronous serie compensator (SSSC)}

The SSSC is also considered as a series device of FACTS family that is based on power electronics to control power flow. The device injects a voltage Vs in series with the transmission line where it is connected [10].

\subsection{Static synchronous compensator (STATCOM)}

Traditionally, the STATCOM is a voltage-regulating device. It is based on a power electronics VSC that can be installed in the great EN to improve its operation $[9,10]$.

\subsection{Unified power flow controller (UPFC)}

The UPFC can be considered as a combination of two FACTS systems; series and shunt device $[8,9]$. The device also used to improve the transient stability of the EN systems [11].

\subsection{Thyristor controller voltage reactor (TCVR)}

To modify the node voltage level, TCVRs are used as a shunt device. This latter has been discussed by Eskandar and Ravi [8-10].

\subsection{Thyristor controller phase shifter (TCPST)}

In the regulation of voltage angle between the sending end and the receiving end of the transmission line, the (TCPST) device is used and represented by an ideal phase shifter [8].

\section{GENETIC ALGORITHM DEFINITION}

In optimization methods, Genetic Algorithm (GA) is a search-based optimization method based on the principles of natural selections and genetics. This technique has been proposed by John Holland in Michigan University. This technique is applied in several area and used to find nearoptimal or optimal solutions to overcome problems that would take otherwise a lifetime to be solved. The used Algorithm in this method has a simple form, which is easy to implement compared to another algorithms.

\section{PROBLEM FORMULATION}

The search of optimal placements of FACTS devices in EN is based on maximizing load ability of the existing network without any topological modification in this later. We will maximize the network load ability represented by lambda factor $(\lambda)$. We will also penalize all parameters by load factor (lambda) with respect to the stop criterion of the used algorithm.

\section{OBJECTIVE FUNCTION}

The objective function to maximize the power system loadability could be formalized as follows:

$$
F=\max \{\lambda\}
$$

where, $(\lambda)$ is the load factor

To simplify the enforcement of the process constraints where the FACTS devices are placed at random locations. The fitness function $\mathrm{F}_{\mathrm{t}}$ is firstly defined, then the two terms that are targeted separately, the first term in line overloading Ove ${ }_{1}$ and the second term is related to bus voltage violations $\mathrm{Vio}_{\mathrm{B}}$, are included as follows

$$
F_{t}=2-\left\{\prod_{\text {Line }} \text { ove } e_{L}+\prod_{\text {Bus }} V_{\text {ino }}\right\}
$$

$F_{t}$ is a fitness function.

\section{FLOWCHART OF OPTIMIZATION}

In the Figure 1, the flowchart of optimization using GA method is presented. In addition, the parameters of GA method used in simulation are given in Table 1.

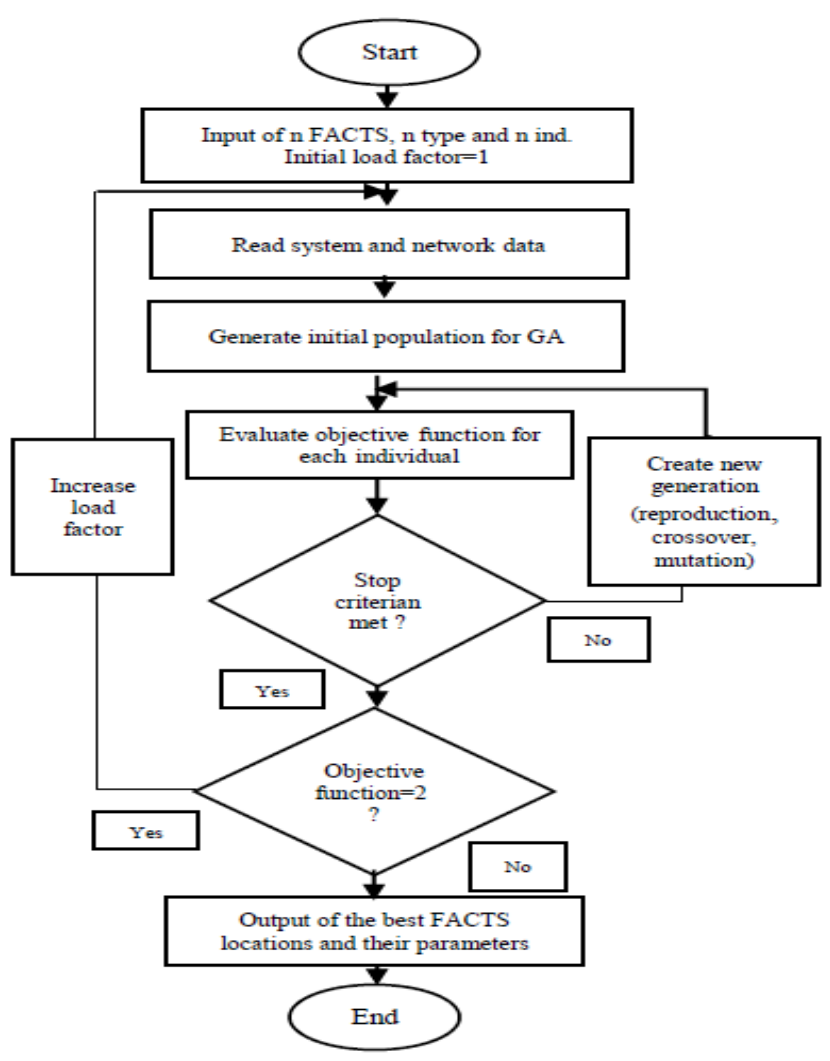

Figure 1. Flowchart of optimization using GA technique 
Table 1. The typical parameters of GA used in simulation

\begin{tabular}{cc}
\hline (GA) Parameter & Values \\
\hline Number of generations & 120 \\
Size of Population & 15 \\
elite count & 4 \\
Crossover fraction & 0.8 \\
Fitness limit & $1 \mathrm{e}^{-6}$ \\
Time limit & inf \\
\hline
\end{tabular}

\section{SIMULATION RESULT}

The optimization algorithm has been applied on three test systems; IEEE30, IEEE57 and IEEE118.

\subsection{IEEE 30 BUS}

In the figure 2, the influence of optimal placements of FACTS devices proposed on bus voltage with power system loadability at lambda $=1.24$ is presented. From the simulation result, total voltage deviation equal to 0.017 with optimal placement and 0.031 without FACTS. Those results show the efficiency of this technique to improve a voltage in all buses of power system.

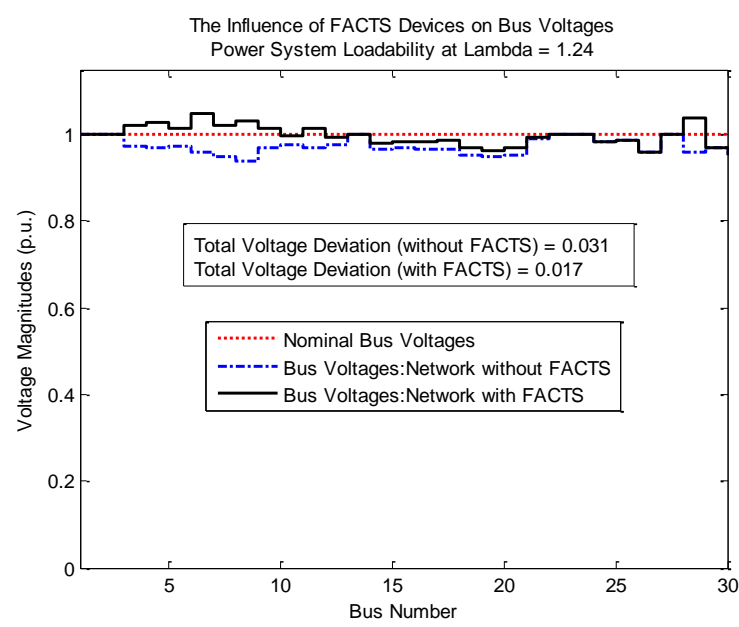

Figure 2. Voltage magnitudes (30 BUS)

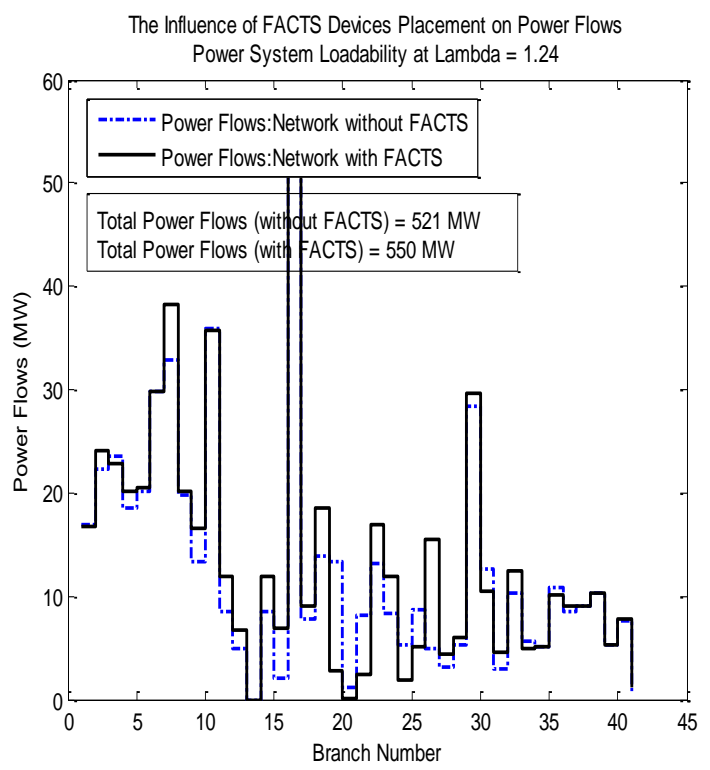

Figure 3. Power flows (30 BUS)
In the Table 2, the type of FACTS devices proposed for each electrical network, the optimal placements of FACTS devices with their best parameters and total power flow with and without FACTS devices are presented.

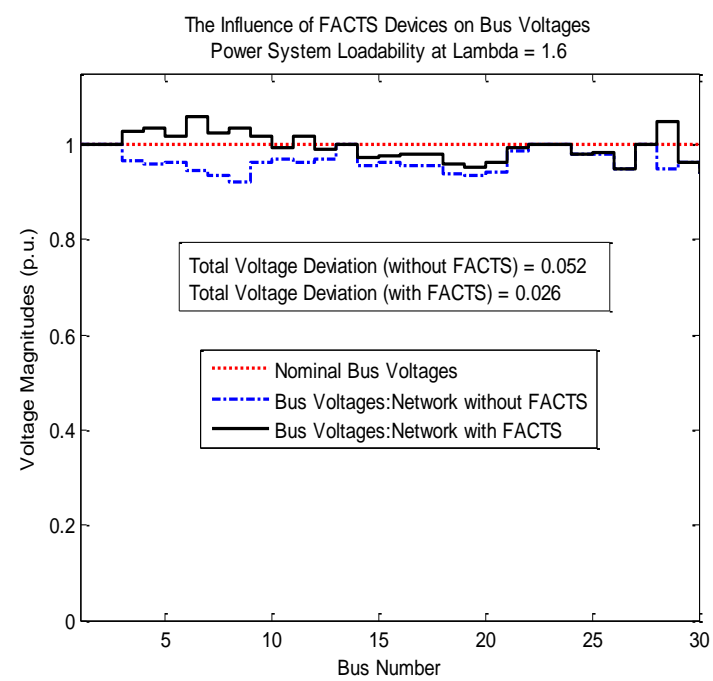

Figure 4. Voltage magnitudes (30 BUS)

\subsection{Simulation for 57 BUS}

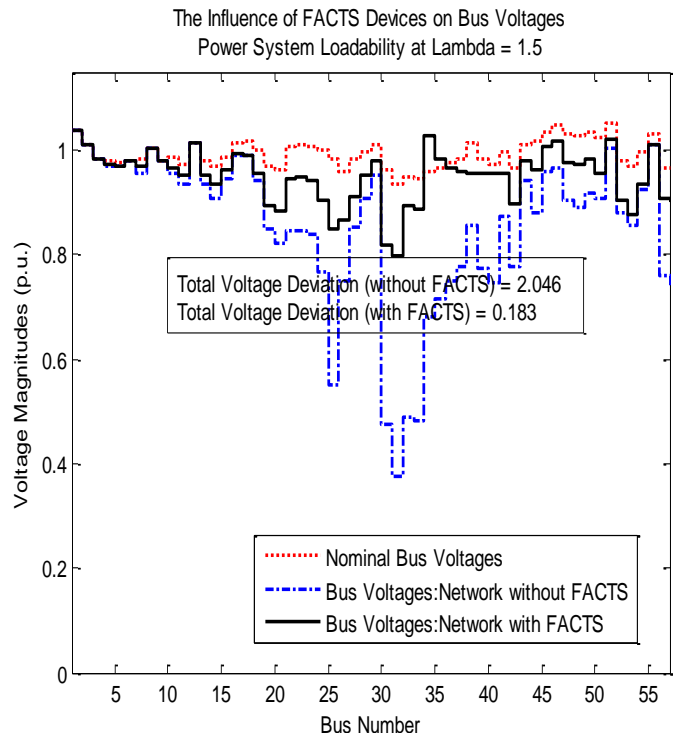

Figure 5. Voltage magnitudes (57 BUS)

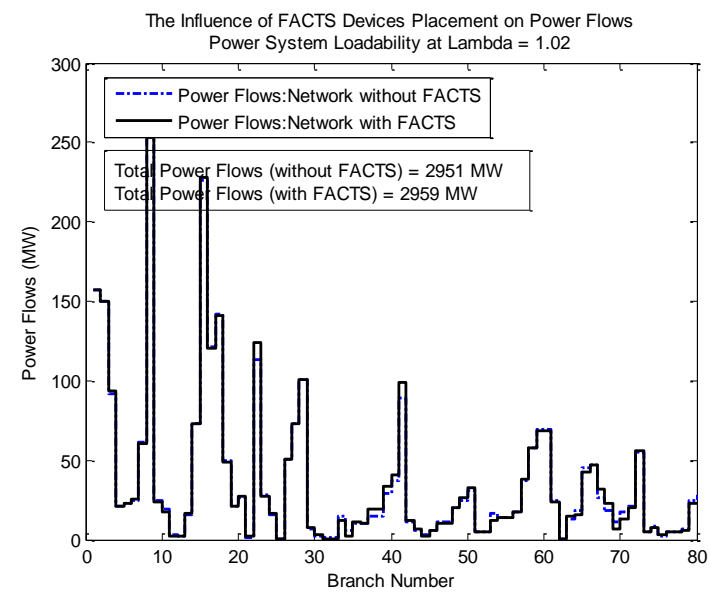

Figure 6. Power flows (57 BUS) 
Table 2. Optimal placement of FACTS devices with their best parameters in various test systems

\begin{tabular}{|c|c|c|c|c|c|}
\hline \multirow[b]{2}{*}{ System test } & \multirow[b]{2}{*}{ Type of FACTS Device } & \multirow[b]{2}{*}{ Optimal Location of FACTS } & \multirow{2}{*}{$\begin{array}{c}\text { Best parameters } \\
\text { of FACTS }\end{array}$} & \multicolumn{2}{|c|}{ Total Power Flow } \\
\hline & & & & $\begin{array}{l}\text { Without } \\
\text { FACTS }\end{array}$ & $\begin{array}{c}\text { With } \\
\text { FACTS }\end{array}$ \\
\hline \multirow{5}{*}{30 BUS } & SVC & Branch 06 & -148.7 MVAR & \multirow{5}{*}{$521 \mathrm{MW}$} & \multirow{5}{*}{$550 \mathrm{MW}$} \\
\hline & TCSC & Branch 23 & -0.704 REACTANCE & & \\
\hline & TCVR & Branch 36 & 1.020 Ration & & \\
\hline & TCPST & Branch 26 & -4.975 Degree & & \\
\hline & UPFC & Branch 09 & $0.156 \mathrm{pu}, 330.7$ Degree,-0.076pu & & \\
\hline \multirow{9}{*}{57 BUS } & SVC & BUS 34 & $-44.598 \mathrm{MVAr}$ & \multirow{9}{*}{$2951 \mathrm{MW}$} & \multirow{9}{*}{ 2959MW } \\
\hline & SVC & Bus 1 & -76.833 MVAr & & \\
\hline & TCSC & Branch 6 & -0.449 Reactance & & \\
\hline & TCSC & Branch 73 & -0.389 Reactance & & \\
\hline & TCVR & Branch 76 & 1.033 Ratio & & \\
\hline & TCVR & Branch 39 & 1.009 Ratio & & \\
\hline & TCPST & Branch 41 & -4.210 Degree & & \\
\hline & TCPST & Branch 29 & -2.263 Degree & & \\
\hline & UPFC & Branch 73 & $0.189 \mathrm{pu}, 339.023$ Degree, $-0.029 \mathrm{pu}$ & & \\
\hline \multirow{5}{*}{118 BUS } & SVC & Branch 2 & $6.019 \mathrm{e}-5 \mathrm{pu}$ & \multirow{5}{*}{$13687 \mathrm{MW}$} & \multirow{5}{*}{$14044 \mathrm{MW}$} \\
\hline & TCSC & Branch 128 & $0.062764 \mathrm{pu}$ & & \\
\hline & TCVR & Branch 116 & $0.03893 \mathrm{pu}$ & & \\
\hline & TCPST & Branch 122 & $0.24256 \mathrm{pu}$ & & \\
\hline & UPFC & Branch 139 & $0.79 \mathrm{pu}, 2325$ Degree, $0.25 \mathrm{pu}$ & & \\
\hline
\end{tabular}

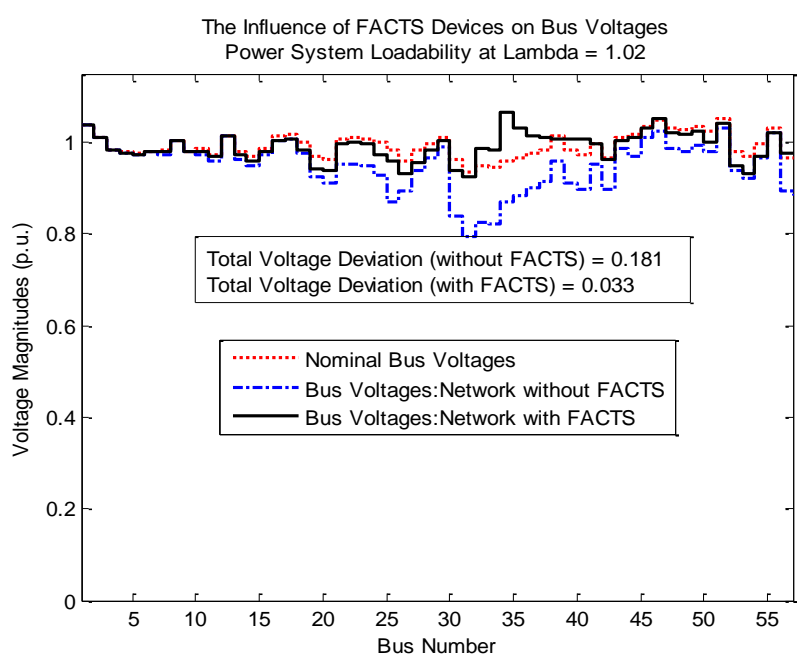

Figure 7. Voltage magnitudes (57 BUS)

\subsection{Simulation for IEEE 118 BUS}

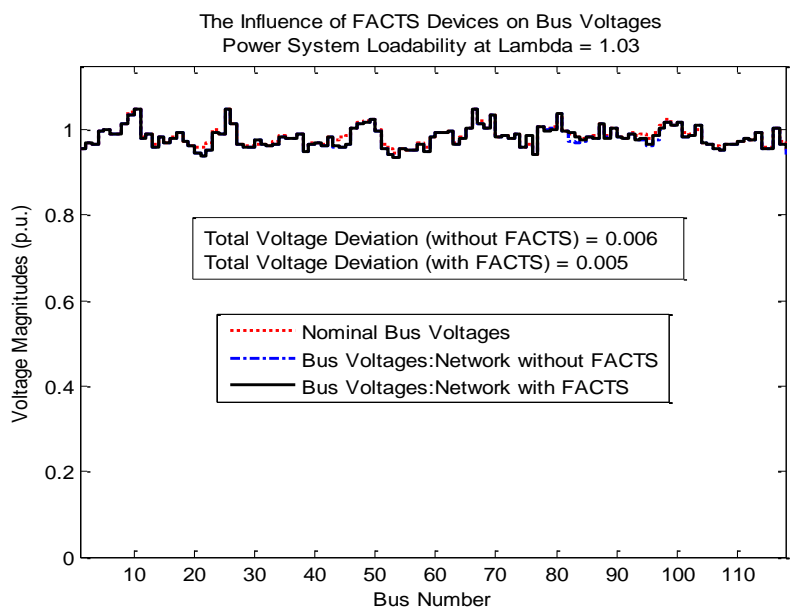

Figure 8. Voltage magnitudes (118 BUS)

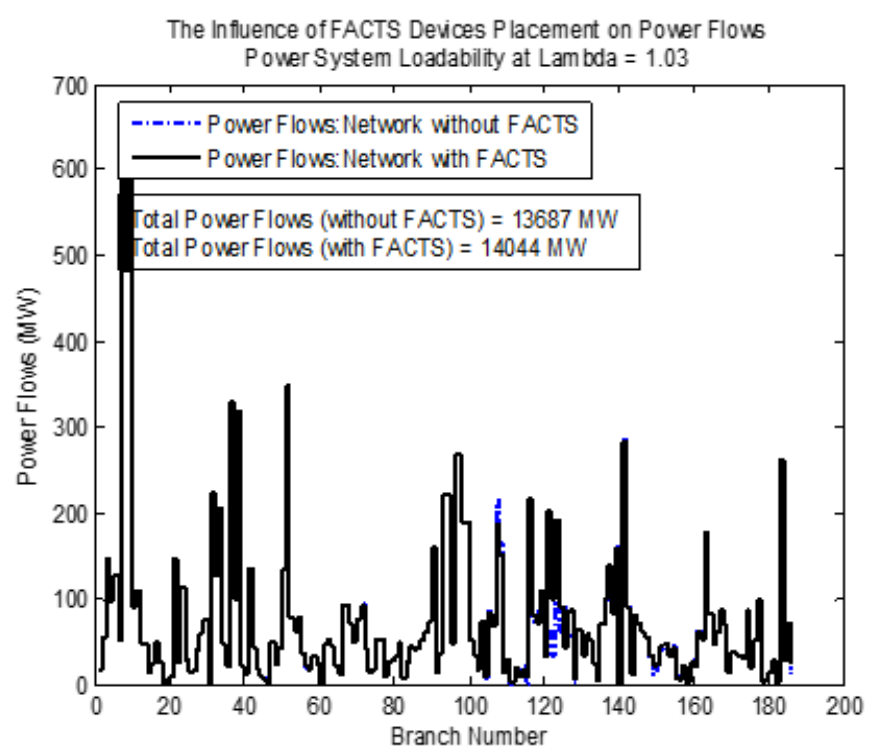

Figure 9. Power flows (118 BUS)

\section{CONCLUSION}

The method proposed in this work was implemented in the MATLAB/Environment. The presented technique aimed to investigate the optimal placement of FACTS devices associated with their suitable parameters based on the maximum load factor in the network. The GA method was used to optimize the appropriate emplacements of FACTS devices in the network, also the investigation of the best parameters of each device was also taken into consideration.

The considered method in this work was tested with various networks such as IEEE 30 bus, 57 bus and 118 bus. First of all, the voltage deviation in all buses of the network was analyzed and determined by the optimal locations of the FACTS device.

The optimal locations and parameters of each FACTS could contribute to enhance total voltage deviation in all bus in the network; therefore, this approach is considered as a novel 
technique for improving global stability of power system and particularly to enhance voltage stability.

Similarly, Particle Swarm Optimization (PSO) would be used as an evolutionary method to search the optimal placements of the FACTS device; therefore, the advantages and disadvantages of each technique could be compared and evaluated.

\section{REFERENCES}

[1] Tejaswini, A.G., Khokhar, K.K., Sahare, T., Verma, N., Bakhtiyar, N. (2015). Study of different methods of voltage stability analysis. International Journal of Advanced Research in Electrical, Electronics and Instrumentation Engineering, 4(11): 8670-8677. https://doi.org/10.15662/IJAREEIE.2015.0411019

[2] Inkollu, S.R., Kota, V.R. (2016). Optimal setting of FACTS devices for voltage stability improvement using PSO adaptive GSA hybrid algorithm. Engineering Science and Technology, an International Journal, 19(3): 1166-1176. https://doi.org/10.1016/j.jestch.2016.01.011

[3] Naganathan, A., Ranganathan, V. (2016). Improving voltage stability of power system by optimal location of FACTS devices using bio-inspired algorithms. Circuits and $\quad$ Systems, 7(6): 805-813. https://doi.org/10.4236/cs.2016.76069

[4] Ara, A.L., Kazemi, A., Niaki, S.N. (2011). Multiobjective optimal location of FACTS shunt-series controllers for power system operation planning. IEEE Transactions on Power Delivery, 27(2): 481-490. https://doi.org/10.1109/TPWRD.2011.2176559

[5] Gaur, D., Mathew, L. (2018). Optimal placement of FACTS devices using optimization techniques: A review. In IOP Conference Series: Materials Science and Engineering, $\quad 331(1)$ : 012023. https://doi.org/10.1088/1757-899X/331/1/012023

[6] Sarda, J.S., Chauhan, M.J., Pandya, V.B., Patel, D.G. (2012). Optimal location of multi-types of FACTS devices using genetic algorithm. International Journal of Research in Computer Science, 2(3): 11-15.

[7] Ngoat, T.T. (2013). Assessment of the effectiveness of two coordinated systems: SVC-PSS and STATCOMPSS for improving transient stability of power system. International Journal of Computer and Electrical
Engineering, 5(4): 414.

[8] Ravi, K., Rajaram, M., Edward, J.B. (2011). Hybrid particle swarm optimization technique for optimal location of FACTS devices using optimal power flow. European Journal of Scientific Research ISSN, 142-153.

[9] Taki, F., Shishebori, A., Abazari, S., Markadeh, G.A. (2010). Comparison of ANFIS based SSSC, STATCOM and UPFC controllers for transient stability improvement. Majlesi Journal of Electrical Engineering, 4(4). https://doi.org/10.1234/mjee.v4i4.422

[10] Gholipour, E., Saadate, S. (2005). Improving of transient stability of power systems using UPFC. IEEE Transactions on Power Delivery, 20(2): 1677-1682. https://doi.org/10.1109/TPWRD.2005.846354

[11] Krishnasamy, V. (2011). Genetic algorithm for solving optimal power flow problem with UPFC. International Journal of Software Engineering and Its Applications, $5(1)$

[12] Yang, X.S. (2010). A new metaheuristic bat-inspired algorithm. In Nature Inspired Cooperative Strategies for Optimization (NICSO 2010), 65-74. https://doi.org/10.1007/978-3-642-12538-6_6

[13] Shaheen, H.I., Rashed, G.I., Cheng, S.J. (2011). Optimal location and parameter setting of UPFC for enhancing power system security based on differential evolution algorithm. International Journal of Electrical Power \& Energy $\quad$ Systems, 33(1): 94-105. https://doi.org/10.1016/j.ijepes.2010.06.023

[14] Machavarapu, S., Rao, M.V.G., Rao, P.V.R. (2019). Machine learning algorithm based static VAR compensator to enhance voltage stability of multimachine power system. Mathematical Modelling of Engineering Problems, 6(4): 641-649. https://doi.org/10.18280/mmep.060420

[15] Machavarapu, S., Rao, M.V.G., Rao, P.V.R. (2019). Modelling and optimal siting of static VAR compensator to enhance voltage stability of power system with uncertain load. Advances in Modelling and Analysis C, 74(2-4): 111-116. https://doi.org/10.18280/ama_c.742411

[16] Issam, G., Sabir, M. (2019). A new adaptive neuro-fuzzy inference system (ANFIS) and PI controller to voltage regulation of power system equipped by wind turbine. Italian Journal of Engineering Science, 21(2): 149-155. 